\title{
Molecular characterization of new isolates of the entomopathogenic fungus Beauveria bassiana and their efficacy against the tobacco caterpillar, Spodoptera litura (Fabricius) (Lepidoptera: Noctuidae)
}

\author{
Sushant Dhar, Vikas Jindal* (D, Monu Jariyal and V. K. Gupta
}

\begin{abstract}
Thirteen fungal isolates, having characteristics similar to Beauveria bassiana, were isolated from field soils of Punjab, India, on Beauveria-specific selective medium (BS medium). Molecular screening of the B. bassiana isolates, using PCR amplification with B. bassiana-specific primer and nucleotide sequence analysis of ITS region, confirmed only three isolates as B. bassiana (now named as BbR1, BbR2, and BbR3) along with MTCC 2028 reference isolate. Comparative RAPD-PCR amplification with ten different RAPD primers showed that all the three isolates were closely related. Genetic relatedness dendrogram developed, using RAPD-PCR data by UPGMA, measured the quantitative description of genetic diversity and showed that the standard isolate MTCC2028 was 58\% similar to new isolates. B. bassiana isolates achieved their maximum growth during the optimum incubation period of 7 days. Significant mortality rates of the tobacco caterpillar, Spodoptera litura (Fabricius) (Lepidoptera: Noctuidae), were recorded at all the tested concentrations of conidial suspensions $\left(10^{3}\right.$ to $10^{7}$ conidia $\left.\mathrm{ml}^{-1}\right)$ of B. bassiana. BbR2 was found to be the most potential local isolate, causing the maximum mortality (83.33\%) of $S$. litura, with $\mathrm{LC}_{50}$ value of 935.663 conidia $\mathrm{ml}^{-1}$, followed by BbR3 (74. 33\%), BbR1 (72.22\%), and BbM1 (67.12\%) isolates.
\end{abstract}

Keywords: Beauveria bassiana, Isolates, Molecular identification, Spodoptera litura, Efficacy

\section{Background}

Insect pests continue to pose a major threat for achieving higher production of agricultural crops. India loses $16.80 \%$ of its crops due to various insect pests, resulting in huge annual revenue loss estimated to be 36 billion USD (Dhaliwal et al. 2015). Synthetic pesticides, as an integral part of modern crop management practices, are significantly contributing to the improved agricultural production in the country by minimizing yield losses. To manage the insect pests, consistent indiscriminate applications of synthetic chemicals have resulted in serious negative concerns. These include emergence of high levels of pesticide resistance in many pest species, environmental toxicity, fishery losses, ground and surface water

\footnotetext{
* Correspondence: vikas_ento@pau.edu

Insect Molecular Biology Laboratory, Department of Entomology, Punjab Agricultural University, Ludhiana 141004, India
}

contamination, depletion of rhizosphere microflora, food safety hazards, and human health concerns (Shetty and Sabitha 2009).

Tobacco caterpillar, Spodoptera litura (Fabricius) (Lepidoptera: Noctuidae), is an extremely serious pest of agricultural crops. It causes severe damage to more than 115 plant species including pulses, cotton, cabbage, cauliflower, castor, groundnut, and oilseed crops (Atwal and Dhaliwal 2009). The pest is known to cause severe damage to non $B t$ cotton, cabbage, cauliflower, sunflower, etc. in Punjab. The exhaustive use of insecticides for its management has led to the problem of resistance. Growing public concern over potential health hazards of synthetic pesticides has changed the research towards more environmental friendly insect pest management tactics.

Among biocontrol agents, a number of entomopathogenic fungal species (EPF) have shown a promising 
potential against number of insect pests. Beauveria bassiana (Bals.) Vuill. is one of the most common EPF, occurring in multiple hosts, and is ubiquitous in most regions of the world (Meyling et al. 2009 and Roy et al. 2010). The genes involved in virulence of $B$. bassiana have been compiled by Valero-Jimenez et al. (2016).

Polymerase chain reaction (PCR)-based random amplified polymorphic DNA (RAPD) has been extensively used to differentiate strains of $B$. bassiana. RAPD analysis has been utilized to generate unique PCR products or amplicons in filamentous fungal species of interest to be converted into species-specific sequence-characterized amplified region (SCAR) markers (Li et al. 1999). Besides these, nucleotide differences in the ITS regions of the ribosomal DNA (rDNA-ITS) have been used to assess the genetic variability among Beauveria spp. (Imoulan et al. 2017 and Badotti et al. 2017). Hegedus and Khachatourians (1996) developed a B. bassiana-specific PCR-based technology for molecular identification of $B$. bassiana isolates.

$B$. bassiana has long been recognized as a potential biocontrol agent, and the compatibility of this fungus with chemical insecticides for use in IPM has already been evaluated and established (Oliveira et al. 2003). Specific strains of $B$. bassiana have been developed into number of commercial biopesticides (BotaniGard ${ }^{\circ} \mathrm{ES}$, BotaniGard ${ }^{\circ} 2 \mathrm{WP}$, Naturalis ${ }^{\circ} \mathrm{TNO}$ and $\mathrm{Mycotrol}^{\circ}$ ) for control of various insect pests on wide range of crops, vegetables, and forest trees (Strasser et al. 2001). In India, the commercial biopesticides have been recommended for control of different insect pests on different crops, but their application has shown only a reduced efficiency attributed to differences in susceptibility of target insect pests or non-adaptability to Indian agro-climatic conditions. Therefore, there is a need to isolate region-specific biopesticide strains to enhance the efficacy of such biopesticides for pest management.

This study aimed to isolate and characterize new isolates of the entomopathogenic fungus, Beauveria species from field soils of Punjab, India, and to evaluate their virulence against $S$. litura, one of the economic pest in the region.

\section{Materials and methods}

\section{Beauveria bassiana isolates}

Standard culture of B. bassiana (BbM1) MTCC 2028 was procured from Microbial Type Culture Collection, Institute of Microbial Technology, Chandigarh, India (Varma et al. 1988). In addition, Beauveria-related species were isolated from different field soils of the state of Punjab, India, using Beauveria-specific selective media (Shimazu and Sato, 1996).

A total of 48 soil samples were collected from different districts of Punjab from fields of different crops (cotton, rice, vegetables, and pulses). About $100 \mathrm{~g}$ soil was collected from four different locations up to the depth of 5 $\mathrm{cm}$ of 1-acre field. The soil samples from different parts of a field were pooled, and a representative sample of $50 \mathrm{~g}$ was suspended in $500 \mathrm{ml}$ of sterile distilled water in a conical flask. The contents were kept on a rotary shaker (200 rpm, $30 \mathrm{~min}, \mathrm{RT}$ ) to dislodge microbial cells and fungal spores from soil particles. After allowing the soil particles to settle for $15 \mathrm{~min}, 100 \mu \mathrm{l}$ of a $10^{-2}$ dilution of the supernatant was plated on Beauveria-specific medium in Petri plates $(90 \mathrm{~mm})$. The plates were incubated at $25^{\circ} \mathrm{C}$ in a BOD incubator for 7 days. The optimal conditions and optimal media for the isolates were followed as per Dhar et al. (2016).

\section{Morphological characterization}

After 7 days of incubation, morphological characteristics of fungal colonies were recorded for their identification as B. bassiana (Draganova et al. 2010). Bits of mycelial growth with sporulating mass were suspended in $1.0 \mathrm{ml}$ of sterile water by vortexing, and $50 \mu \mathrm{l}$ of the same was surface plated on BS medium in fresh Petri plates $(90 \mathrm{~mm})$. The plates were incubated at $25^{\circ} \mathrm{C}$ in a BOD incubator to allow growth of fungal colonies from single spores. After 4 days of incubation, individual colonies were transferred on slants of BS medium and master cultures were allowed to grow and then stored at $4{ }^{\circ} \mathrm{C}$ until used.

\section{Infectivity of $B$. bassiana isolates against Galleria mellonella larvae}

The entomopathogenic potential of 13 isolated fungal isolates (out of 48) showing B. bassiana characteristics was tested against G. mellonella larvae, following the method of Ali-Shtayeh et al. (2002). Isolates were grown on PDA (potato dextrose agar) medium in slants for 10 days until sporulation. Small fungal hyphae bits were incised into $1.5-\mathrm{ml}$ micro centrifuge tubes containing $1 \mathrm{ml}$ of sterilized distilled water and $0.05 \%$ Triton $\mathrm{X}$. The tubes were then vortex mixed. Ten third-instar G. mellonella larvae (obtained from infected spent honey combs from Apiculture Farm, Punjab Agricultural University, Ludhiana, India) were dipped into each fungal suspension for $5 \mathrm{~s}$. The larvae were then placed on moisturized sterile filter papers in sterile Petri plates and incubated in the dark at 25 ${ }^{\circ} \mathrm{C}$. Petri dishes were checked daily for larval mortality (Fig. 1). The control larvae were dipped in Triton $X$ solution and incubated. After inoculating the G. mellonella larvae with Beauveria isolate, insect mortality was observed after 7 days with fungal mycelium emerging out of the larvae. Small bits of fungal growth emerging out of dead larvae were inoculated onto PDA agar until sporulation was observed. Based on infectivity and morphological features, three isolates were selected for further studies. 


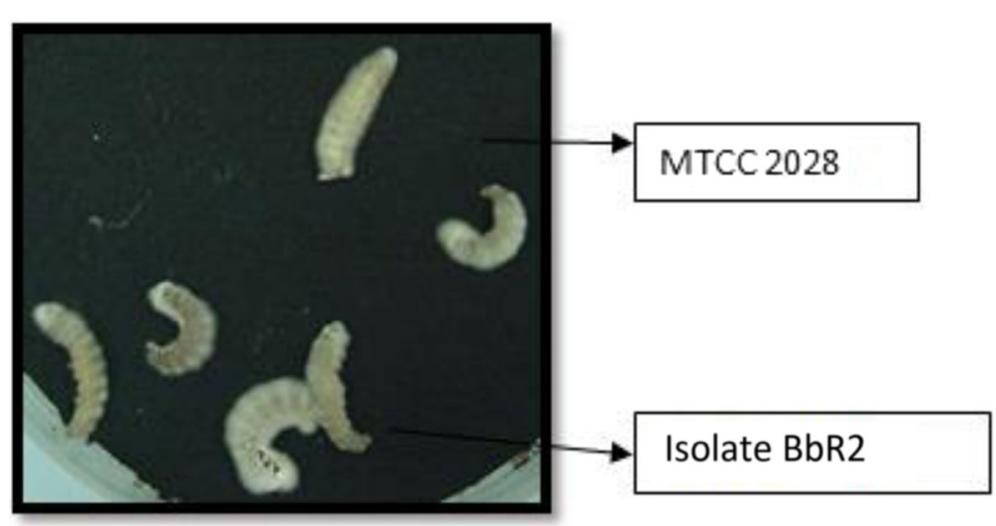

Fig. 1 Galleria mellonella larvae showing infection with two different fungal isolates establishing their entomopathogenic characteristics. Galleria mellonella larvae infected with fungal isolate BbR2 and Beauveria bassiana MTCC 2028

Molecular analysis of $B$. bassiana isolates for genetic relatedness

\section{DNA extraction}

Beauveria isolates were cultivated in $(50 \mathrm{ml})$ PD broth at $25^{\circ} \mathrm{C}$. The mycelial biomass was harvested on a filter paper and washed three times with sterile distilled water. Fresh mycelial biomass $(100 \mathrm{mg})$ for each isolate was grounded to fine powder in liquid nitrogen, using a sterilized pestle and mortar. The biomass powder, suspended in CTAB solution $(5 \mathrm{ml})$, was incubated at $65^{\circ} \mathrm{C}$ for $30 \mathrm{~min}$. The solution was extracted by chloroform:isoamyl alcohol $(24: 1)$ solution $(5 \mathrm{ml})$ by vortexing. After centrifugation $(10,000 \mathrm{rpm}, 10 \mathrm{~min})$, the upper DNA containing aqueous phase was transferred into a fresh centrifuge tube $(15 \mathrm{ml})$ and total DNA was precipitated by an equal volume of isopropanol $(5 \mathrm{ml})$. The DNA was collected in a pellet by centrifugation $(12,000 \mathrm{rpm}, 5 \mathrm{~min})$; the pellet was washed once with $70 \%$ ethanol, allowed to air dry for 5-10 min, and was suspended in $100 \mu \mathrm{l}$ of TE (10 mM Tris.cl-1 mM EDTA, pH 8.0) solution.

\section{Molecular identification}

Total DNA from different fungal isolates was PCR amplified, using $B$. bassiana-specific primers (P1-5'-AAGC TTCGACATGGTCTG-3' and P3-5'-GGAGGTGGTGA GGTTCTGTT-3' primers) (Hegedus and Khachatoriuans 1996), using a PCR amplification program $\left(95^{\circ} \mathrm{C}\right.$ for $5 \mathrm{~min}$ (preheating), $95^{\circ} \mathrm{C}$ for $1 \mathrm{~min}, 54^{\circ} \mathrm{C}$ for $1 \mathrm{~min}, 72^{\circ} \mathrm{C}$ for 2 min ( 28 cycles), $72^{\circ} \mathrm{C}$ for $10 \mathrm{~min}$; final extension) and stored at $4{ }^{\circ} \mathrm{C}$ until used. The amplification of the desired DNA band of $524 \mathrm{bp}$ was observed on $1.2 \%$ agarose gel in TAE. ITS region from all the three isolates was amplified, using bbITS-F/SR6R (aagtataagtcgtaacaagg) and bbITS-R/ LR1 (ggttggtttctttcct) (Lane et al. 1985 and Vilgalys and Hester 1990) and cloned in pGEM-Teasy vector. The nucleotide sequence was determined and compared to NCBI database for confirmation of these isolates as B. bassiana.

\section{Analysis of RAPD-PCR profiles for genetic relatedness}

The genetic relatedness among different $B$. bassiana isolates along with standard B. bassiana MTCC 2028 was assessed through comparative RAPD-PCR (random amplified polymorphic DNA-polymerase chain reaction) employing RAPD primers (OPF-12, OPF-03, OPE-01, OPB-07, OPB-10, OPC-04, OPG-03, OPL-08, OPN-10, and OPP-04), using an annealing temperature of $42{ }^{\circ} \mathrm{C}$ (38 cycles). The amplified DNA fragments were analyzed through agarose gel electrophoresis and banding pattern photographed in gel documentation system. RAPD banding patterns were manually scored and processed by NTSYS software for developing genetic relatedness dendrogram by UPGMA (NTSYS pc version 2.02) (Rholf 1998), a measure of quantitative description of genetic diversity. All the individual bands in RAPD banding profile of different $B$. bassiana isolates were scored for presence (1) or absence (0) of all the individual bands.

\section{Spodoptera litura bioassay}

S. litura larvae were collected from infested castor plants from Punjab Agricultural University, Ludhiana, and maintained in the laboratory at $25^{\circ} \mathrm{C}$ and $70-75 \%(\mathrm{RH})$. Subsequently, the larvae were reared individually on castor leaves. Castor leaves were surface sterilized by alcohol to prevent any possible contamination (Sasidharan and Varma 2005).

The conidia of the three isolates and the standard were revived on PDA medium plates at $25 \pm 2{ }^{\circ} \mathrm{C}$ until they developed dense conidiation (7-10 days). The conidia were harvested from 2-week-old cultures by flooding the plates with sterile aqueous (0.05\%) Tween-80 (Sigma USA) solution. The suspension was filtered through sterile muslin cloth to remove any mycelial fragments (Sasidharan and Varma 2005). The concentration of conidia was determined by a Neubauer hemocytometer, under a phase contrast microscope (Zeiss), and adjusted by dilution with Tween- 80 solution to $1.0 \times 10^{8}$ conidia/ 
$\mathrm{ml}$, which served as the stock suspension. The stock concentration was diluted to different suspensions with conidial count $\left(1 \times 10^{3}, 1 \times 10^{4}, 1 \times 10^{5}, 1 \times 10^{6}\right.$, and $1 \times$ $10^{7}$ conidia $\mathrm{ml}^{-1}$ ) for each $B$. bassiana isolate.

The second instar of $S$. litura larvae was dipped in different concentrations of conidial suspensions of each $B$. bassiana isolate for $5 \mathrm{~s}$ in a plastic container $(8 \mathrm{~cm}$ diameter and $10 \mathrm{~cm}$ height). After dipping, the larvae were shifted on a sterile filter paper for soaking excess moisture and then released on a surface-sterilized castor leaves in individual sterile containers. The food was changed daily until larval death or pupation. In the control, the larvae were dipped in $0.05 \%$ Tween- 80 solution. Daily observations were made to observe the development of fungal mycosis and consequent insect mortality.

\section{Statistical analysis}

The corrected mortality rate was calculated, using Abbott's formula (Abbott 1925). The median lethal concentrations $\left(\mathrm{LC}_{50}\right)$ were also estimated by probit analysis, using the computer Program POLO (LeOra Software, 1987). The data were subjected to ANOVA, and the least significant difference was calculated, using a factorial CRD design.

\section{Results and discussion}

\section{B. bassiana isolates from soil}

Out of 48 soil samples collected, 13 fungal species on selective BS medium showed morphological and cultural characteristics similar to Beauveria species. Colonies were round, lightly raised with white powdery surface, lightly downy with circular rings. White powdery translucent mycelium shows radial growth. Condiospores were densely clustered in whorls, one celled, hyaline, smooth, and short.

\section{Screening of Beauveria isolates by Galleria infectivity method}

Virulence of all the 13 fungal isolates was evaluated first against G. mellonella larvae (Ali-Shtayeh et al. 2002). Out of 13 fungal isolates, only the 3 isolates 2, 9, 31 (now named as BbR1, BbR2, and BbR3) effectively caused mortality of G. mellonella larvae within 5-7 days coupled with a white muscardine growth of fungal mycelium (typical of B. bassiana) (Fig. 1).

In order to acquire cultures with optimum virulence, the selected 3 fungal isolates and the standard B. bassiana (MTCC 2028 culture, called as BbM1) were re-isolated from dead G. mellonella larvae that had been infected with each respective fungal isolate. Small bits of the fungal mass were transferred and cultured in PDA medium slants. All the cultures, processed for a single spore isolation and cultured from an individual isolated fungal colony, were used as master cultures for all subsequent studies.

\section{Molecular identification of $B$. bassiana isolates}

Total DNA, isolated from all the 13 different fungal isolates, was PCR amplified by $B$. bassiana-specific primers P1 and P3. DNA fragment of size approximately $520 \mathrm{bp}$ was amplified. The PCR product of only the same 3 isolates, viz. $\mathrm{BbR} 1, \mathrm{BbR} 2$, and $\mathrm{BbR} 3$, and BbM1 reference MTCC2028 isolate was close to the expected $524 \mathrm{bp}$. This indicated that out of the 13 fungal isolates, only 3 strains (Fig. 2) were B. bassiana. The rest showed different types of amplification patterns, which could be non-virulent species of Beauveria that are closely related to B. bassiana in morphological characteristics. Based on ITS nucleotide sequence analysis, the same 3 isolates were shown to have maximum homology with $B$. bassiana sequences in the NCBI database. The nucleotide sequences of the 3 isolates (BbR1, BbR2, and BbR3) were submitted to NCBI GenBank with accession nos. MG670098.1, MG670100.1, and MG670102.1, respectively (Geetika Banta, Personal Communication).

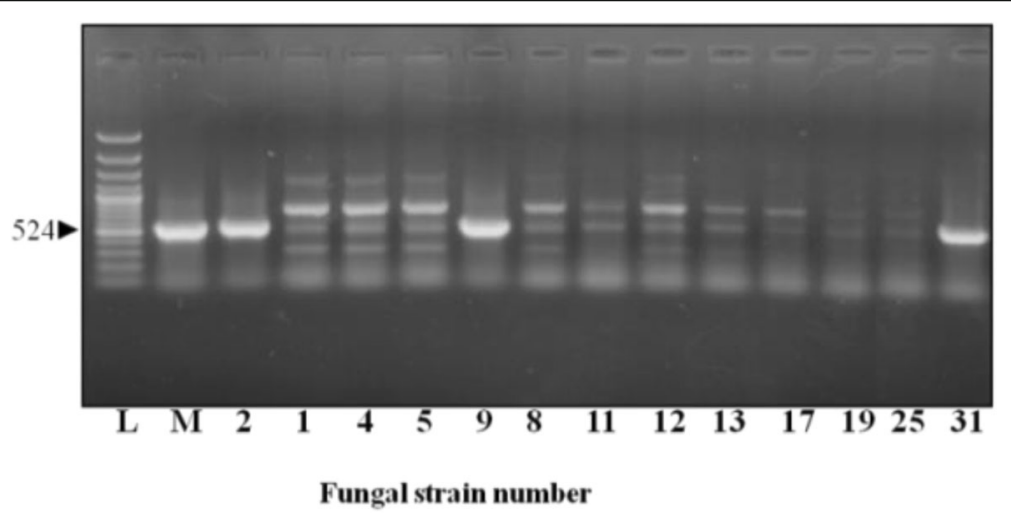

Fig. 2 PCR amplification with Beauveria bassiana-specific primers from different fungal isolates. M is the reference isolate B. bassiana MTCC 2028; $L$ is 100-bp DNA ladder (Fermentas Life Sciences) 

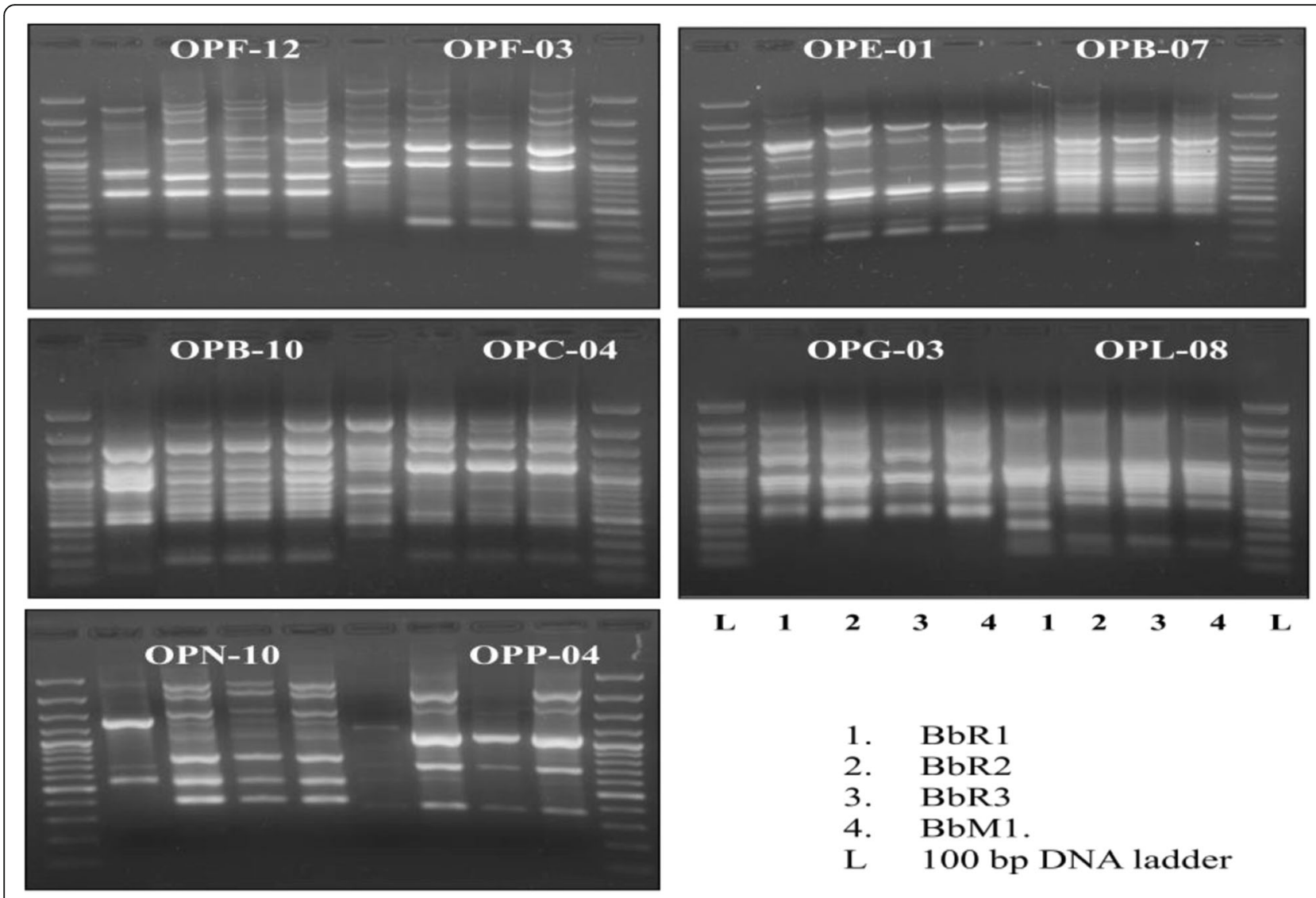

$\begin{array}{llllllllll}\text { L } & 1 & 2 & 3 & 4 & 1 & 2 & 3 & 4 & \text { L }\end{array}$

1. BbR1

2. BbR2

3. BbR3

4. BbM1.

L $\quad 100$ bp DNA ladder

Fig. 3 Comparative RAPD-PCR amplification profile (banding pattern) of different Beauveria bassiana isolates with ten different RAPD primers

\section{Genetic relationship of $B$. bassiana isolates}

Comparative RAPD-PCR was used to examine genetic differences among the new $B$. bassiana isolates, including B. bassiana MTCC 2028. The comparative RAPDPCR banding profile was obtained by ten different random primers (Fig. 3). The comparative banding pattern identified polymorphic marker bands suggesting molecular differences among these B. bassiana isolates, including the reference MTCC2028 isolate.
Genetic relatedness dendrogram as developed, using RAPD data by UPGMA, was used to measure the quantitative description of these genetic differences. This dendrogram indicated that BbR1, BbR2, and BbR3 were closely related. The maximum of $94 \%$ similarity was observed between isolate BbR1 and BbR3, which was similar to BbR2 with $88 \%$ similarity (Fig. 4).

However, these new isolates showed 58\% similarity with BbM1. High genetic divergence of BbM1 from the new

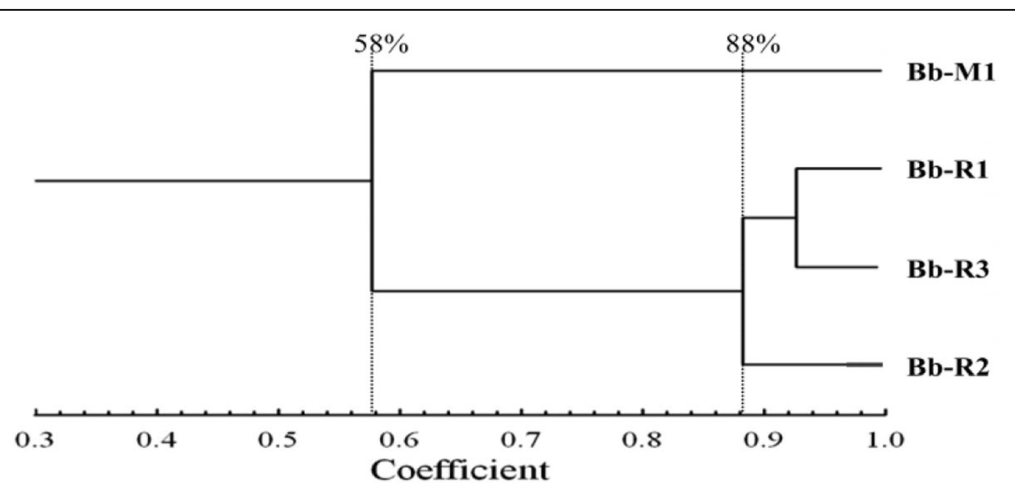

Fig. 4 RAPD-PCR data-based genetic relatedness dendrogram among different Beauveria bassiana isolates 
isolates from Punjab soils in this study may be due to the reason that the former was originally isolated in 1988 from IISR, Lucknow, a distantly located geographic region of India (Varma et al. 1988), and faced repeated sub-culturing at MTCC, Institute of Microbial Technology, Chandigarh.

Various workers have effectively used the RAPD to assess the genetic diversity of different isolates of $B$. bassiana (Kaur and Padmaja 2008; Imoulan et al. 2016; Prabhukarthikeyan et al. 2017). The studies reported the high genetic diversity among local isolates of $B$. bassiana, which supported the diversity of maximum $42 \%$ between standard MTCC2028 and the obtained new isolates.

\section{Efficacy against Spodoptera litura}

All $B$. bassiana isolates were infectious but differed in their aggressiveness, i.e., pest mortality. No larval mortality was observed up to $48 \mathrm{~h}$ post infection, irrespective of B. bassiana isolate. However, after $72 \mathrm{~h}$, mortality was observed in the case of all the isolates and conidial concentrations, ranged between 2.33 and $39.81 \%$ (Fig. 6). The mortality rate increased with the increasing number of conidial concentration used. BbR2 caused the maximum 39.81\% mortality, followed by BbR1 (38.14\%), BbR3 (32.66\%), and BbM1 (32.22\%). Isolate BbR2 caused the maximum mortality at the conidiospore concentration each of $10^{6}$ and $10^{7}$ conidia $\mathrm{ml}^{-1}$ after 96,120 , and $144 \mathrm{~h}$ of treatment and was significantly superior to all isolates (Fig. 6).

After $168 \mathrm{~h}$ of infection, B. bassiana isolate BbR2 was found to be the most effective one, causing a maximum mean mortality of $83.33 \%$, followed by BbR3 (74.33\%) and BbR1 $(72.22 \%)$ at the conc. of $10^{7}$ conidia $\mathrm{ml}^{-1}$. Standard isolate BbM1 caused the least mortality $(67.12 \%)$ at the conc. of $10^{7}$ conidia $\mathrm{ml}^{-1}$ after $168 \mathrm{~h}$ of treatment (Figs. 5 and 6).
Comparison of $\mathrm{LC}_{50}$ values (overlap of confidence intervals) provided a significant difference among the isolates. The most virulent isolate BbR2 (935.663 conidia $\mathrm{ml}^{-1}$ ) had the lowest $\mathrm{LC}_{50}$ values, while BbR1 (4735.68), BbR3 (5725.68), and BbM1 (7934.7) had comparatively high $\mathrm{LC}_{50}$ values (Table 1). Thus, the isolate BbR2, at the concentrations of $10^{6}$ and $10^{7}$ conidia $\mathrm{ml}^{-1}$, was significantly superior over other ones of B. bassiana after all the different hours of infection. Monitoring of infected larvae, which survived mortality after $168 \mathrm{~h}$, suggested that some of these larvae pupated but they did not emerge as adults. Isolate BbR2 proved to be the best among the four isolates.

A significant decrease in the larval period was observed due to $B$. bassiana infection as compared to the control. These results corroborate the findings of Batta and Abu-Safieh (2005) who reported a decrease in the life cycle of red flour beetle, Tribolium castaneum (Herbst), when treated with Metarhizium anisopliae. Khachatourians (1986) also suggested that EPF caused the death of their host due to exhaustion of nutrients and liberation of toxins in the hemolymph. So, nutritional deficiency and toxins produced by EPF drastically affect the development of an insect. Earlier, Sharma et al. (1994) reported physiological changes in Heliothis armigera larvae after injecting them with filtrate of $B$. bassiana culture and found that the toxins destroy the normal balance of physiological system. In the present study, apart from causing insect mortality, B. bassiana isolates caused pupal and adult deformities in S. litura.

Moorthi et al. (2015) tested the efficacy of isolates collected from southern India against S. litura and found the $\mathrm{LC}_{50}$ value of $1.3 \times 10^{3}$, which was comparatively higher than BbR2 isolate (935.663). Ortiz et al. (2016) reported $\mathrm{LC}_{50}$ of $1.07 \times 10^{7}$ to $1.31 \times 10^{10}$ condia $\mathrm{ml}^{-1}$ of different

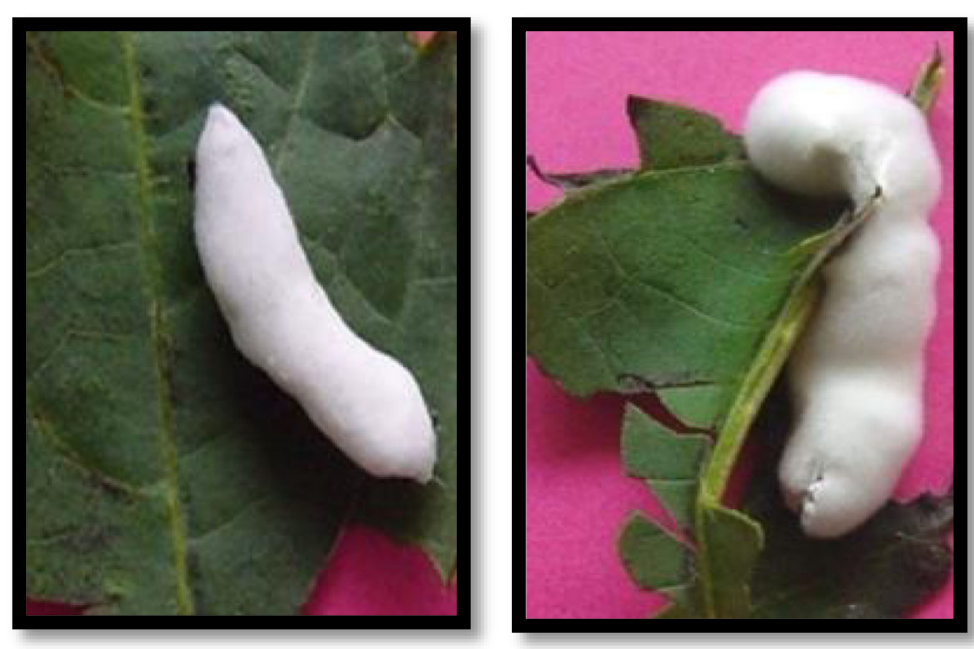

Fig. 5 Beauveria bassiana infection on Spodoptera litura larvae on the seventh day. White fluffy fungal mycelium is seen covering whole of the insect 


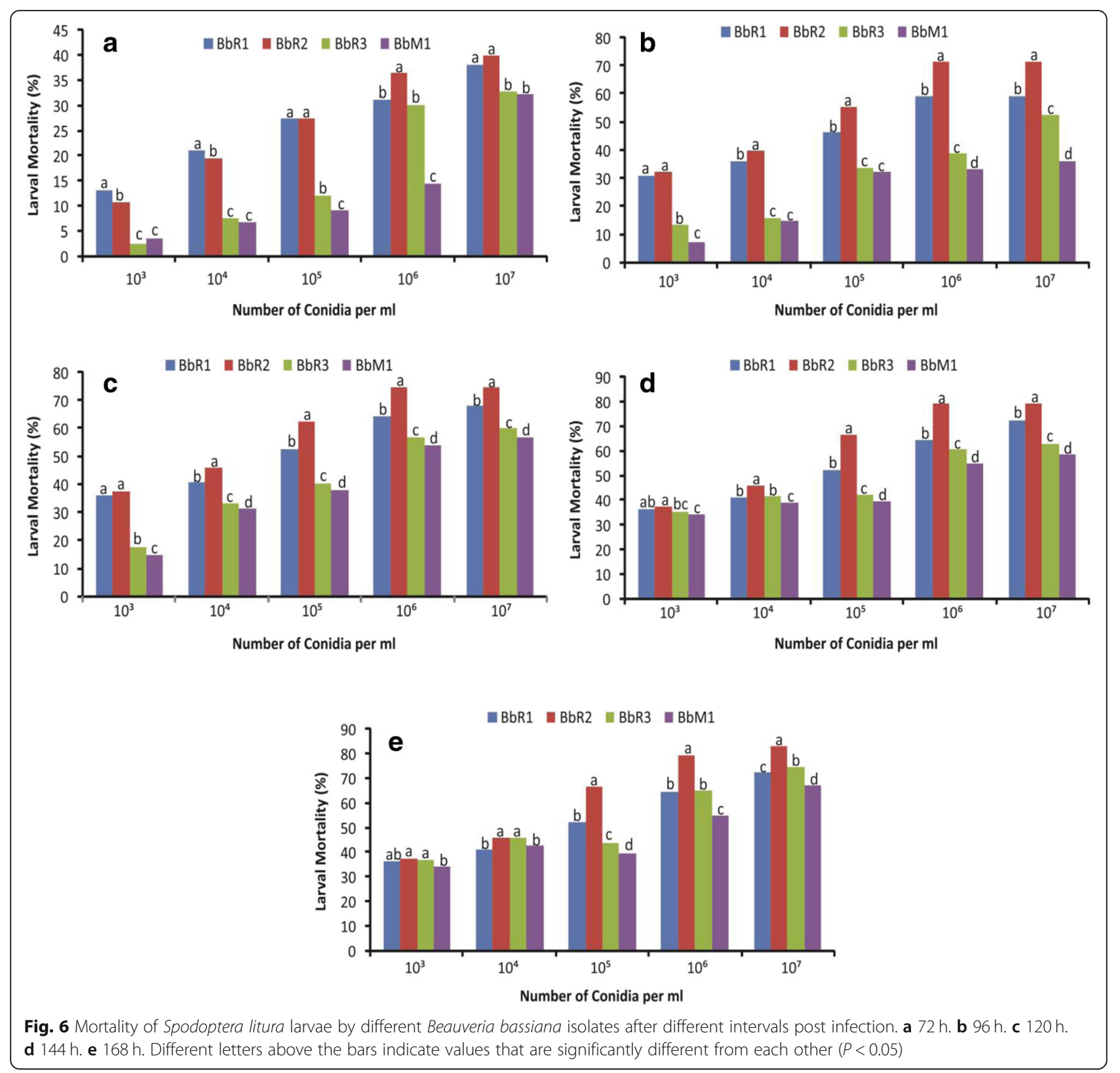

Table $1 L_{50}$ estimates of different Beauveria bassiana isolates from bioassays against second-instar larvae of Spodoptera litura

\begin{tabular}{lllllll}
\hline Isolates & $n$ & Heterogeneity & $\mathrm{LC}_{50}$ & Slope $\pm \mathrm{SE}$ & $X^{2}$ (df) & Limits \\
\hline BbR1 & 30 & 0.07 & 4735.680 & $0.214 \pm 0.076$ & 0.1968 (3) & 2.62 to $45,428.899$ \\
BbR2 & 30 & 0.13 & 935.663 & $0.344 \pm 0.086$ & 0.3805 (3) & 12.633 to 5794.919 \\
BbR3 & 30 & 0.12 & 5725.680 & $0.214 \pm 0.086$ & $0.3904(3)$ & 11.625 to 65,197 \\
BbM1 & 30 & 0.15 & 7934.700 & $0.173 \pm 0.074$ & 0.4552 (3) & 6.9569 to 77,197 \\
\hline
\end{tabular}

$n$ no. of insects treated, $d f$ degrees of freedom, $L C_{50}$ lethal concentration at which $50 \%$ of the insect population gets killed 
isolates of B. bassiana (Bb-Hy, Bb-Rhy, and $\mathrm{Bb}-13$ ) against soybean weevil Rhyssomatus nigerrimus. An Indian isolate DOR B. bassiana (developed by ICAR-Directorate of Oilseed Research, Hyderabad) was found effective for management of Helicoverpa armigera in sunflower (Kumar and Kaur 2017). Nazir et al. (2019) tested isolates of $B$. bassiana (BB-72 and BB-252) against green peach aphid, Myzus persicae, where they recorded high mortality of aphids (95 and 91\%, respectively) after 10 days of treatment. Different isolates from different countries have different potential in the management of different insect pests. Therefore, the isolates of $B$. bassiana found in this study may hold a significance in the management of insect pests in Punjab conditions.

\section{Conclusions}

Three new isolates of $B$. bassiana were isolated from the soils of Punjab, India. RAPD analysis resulted in $88 \%$ similarity among the isolates; however, these were $58 \%$ similar to the standard MTCC2028. A wide range of variations was recorded in the degree of virulence among the three isolates tested. B. bassiana isolate BbR2 showed a higher degree of virulence in the bioassay experiment than the other isolates, and the maximum mortality rate was recorded on the seventh day after treatment.

Field experimentation is necessary to substantiate the present findings on the relative efficacy of B. bassiana isolates against $S$. litura. Further laboratory experiments with different fungal isolates in relation to dosage, time, storage, and stability should be undertaken to find the optimum concentration and efficient application of fungal materials.

\section{Acknowledgements}

Authors are grateful to Department of Entomology, Punjab Agricultural University, Ludhiana, India for providing necessary facilities for this research work. Thanks to Dr. Geetika Banta, Punjab Agricultural University, Ludhiana for sharing the results of ITS based identification of three isolates of Beauveria bassiana. Authors are thankful to Dr. Sheetal Thapar, Punjab Agricultural University, Ludhiana for critically checking the manuscript for improvement of English language.

\section{Funding}

Not Applicable

\section{Author's contributions}

SD carried out the isolation, molecular and bioassay studies, and maintained the culture. VJ designed the bioassay experiment and did the statistical analysis of the bioassay data. $\mathrm{VJ}$ is also involved in preparation, reading, and approval of the manuscript. MJ has contributed equally in the molecular experiments. VKG conceptualized and designed the studies and read and approved the final manuscript. All authors read and approved the final manuscript.

\section{Ethics approval and consent to participate}

Not Applicable

\section{Competing interests}

The authors declare that they have no competing interests.

\section{Publisher's Note}

Springer Nature remains neutral with regard to jurisdictional claims in published maps and institutional affiliations.

Received: 14 November 2018 Accepted: 5 February 2019

Published online: 21 February 2019

\section{References}

Abbott WS (1925) A method for computing the effectiveness of an insecticide. J Econ Entomol 18:265-267

Ali-shtayeh MS, Marai ABBM, Jamous RM (2002) Distribution, occurrence and characterization of entomopathogenic fungi in agricultural soil in the Palestinian area. Mycopathologia156: 235-244

Atwal AS, Dhaliwal GS (2009) Agricultural pests of South Asia and their management. Kalyani Publishers, New Delhi 300p

Badotti F, de Oliveira FS, Garcia CF, Vaz ABM, Fonseca PLC, Nahum LA, Oliveira G, Góes-Neto A (2017) Effectiveness of ITS and sub-regions as DNA barcode markers for the identification of Basidiomycota (fungi). BMC Microbiol 17:-42

Batta YA, Abu Safieh DI (2005) A study of treatment effect with Metarhizium anisopliae and four types of dusts on wheat grain infestation with red flour beetles (Tribolium castaneum Herbs, Coleoptera: Tenebrionidae). J Islamic University Gaza 13(1):11-22

Dhaliwal GS, Jindal V, Mohindru B (2015) Crop losses due to insect pests: global and Indian scenario. Indian J Ent 77(2):165-168

Dhar S, Jindal V, Gupta VK (2016) Optimization of growth conditions and medium composition for improved conidiation of newly isolated Beauveria bassiana strains. Indian J Exp Biol 54:634-643

Draganova SA, Takov DI, Doychev DD (2010) Naturally-occurring Entomopathogenic fungi on three bark beetle species (Coleoptera: Curculionidae) in Bulgaria. Pestic Phytomed 25(1):59-63

Hegedus DD, Khachatourians GG (1996) Identification and differentiation of the entomopathogenic fungus Beauveria bassiana using polymerase chain reaction and single-strand conformation polymorphism analysis. J Invertebr Pathol 67(3):289-299

Imoulan A, Hussain M, Kirk PM, AEI M (2017) Entomopathogenic fungus Beauveria: host specificity, ecology and significance of morpho-molecular characterization in accurate taxonomic classification. J Asia Pacific Ent 20: 1204-1212

Imoulan A, Ibnsouda SK, Meziane AE (2016) Molecular characterization and the effectiveness of native entomopathogenic Beauveria bassiana strains against adults of Mediterranean fruit fly (Ceratitis capitata). J Biosci Biotech Discovery 1:6-16

Kaur G, Padmaja V (2008) Evaluation of Beauveria bassiana isolates for virulence against Spodoptera litura (Fab.) (Lepidoptera: Noctuidae) and their characterization by RAPD-PCR. Afr J Microbiol Res 2:299-307

Khachatourians GG (1986) Production and use of biological pests control agents. Trends in Biotechnol 4(5):120-124

Kumar S, Kaur J (2017) Efficacy of Beauveria bassiana and Bacillus thuringiensis as ecosafe alternatives to chemical insecticides against sunflower capitulum borer, Helicoverpa armigera (Hubner). J Entomol Zool Studies 5(2):185-188

Lane DJ, Pace B, Olsen GJ, Stahl DA, Sogin ML, Pace NR (1985) Rapid determination of 16S ribosomal RNA sequences for phylogenetic analyses. Proc Natnl Acad Sci USA 82:6955-6959

LeOra Software (1987) POLO PC: A User's Guide to Probit or Logit Analysis, Berkley, CA.

Li KN, Rouse DI, Eyestone EJ, German TL (1999) The generation of specific DNA primers using random amplified polymorphic DNA and its application to Verticillium dahliae. Mycol Res 103(11):1361-1368

Meyling NV, Lubeck M, Buckley EP, Eilenberg J, Rehner SA (2009) Community composition, host range and genetic structure of the fungal entomopathogen Beauveria in adjoining agricultural and semi-natural habitats. Mol Ecol 18:1282-1293

Moorthi PV, Balasubramanian C, Ramar M, Murugan K (2015) Biocontrol potential of entomopathogenic fungi against Spodoptera litura. Scientia Agric 12(1):23-27

Nazir T, Basit A, Hanan A, Majeed MZ and Qiu D (2019) In vitro pathogenicity of some entomopathogenic fungal strains against green peach aphid Myzus persicae (Homoptera: Aphididae) Agronomy 9(1):7. https://doi.org/10.3390/ agronomy 9010007

Oliveira CNde, Neves P M \& Kawazoe L S (2003) Compatibility between the entomopathogenic fungus Beauveria bassiana and insecticides used in coffee plantations. Sci Agric 60(4):663-667 
Ortiz SAM, Ruiz JG, López-Guillén G, López LC, Mora JV (2016) Evaluation of the pathogenicity of isolates of Beauveria bassiana against Rhyssomatus nigerrimus. Southwestern Entomol 41(1):41-50

Prabhukarthikeyan SR, Umapathy K, Sornakili A, Thiruvengadam R (2017) Analysis of genetic diversity among different isolates of Beauveria bassiana by RAPDPCR. J Biol Control 31(1):18-24. https://doi.org/10.18311/jbc/2017/15581

Rholf FJ (1998) NTSYSP numerical taxonomy and multivariant analysis version 2.0. Applied biostatistics Inc, New York

Roy HE, Brodie EL, Chandler D, Goettel MS, Pell JK, Wajnberg E, Vega FE (2010) Deep space and hidden depths: understanding the evolution and ecology of fungal entomopathogens. Biocontrol 55:1-6

Sasidharan KR, Varma RV (2005) Laboratory evaluation of Beauveria bassiana (Balsamo) Vuillemin against Indrabela quadrinata Walker (Lepidopteron: Metarbelidae) a key pest of Casuarina equisetifolia L. in Tamil Nadu. J Biol Cont 19(2):197-199

Sharma S, Agarwal GP, Rajak RC (1994) Pathophysiological alterations caused in Heliothis armigera by toxic metabolities of Beauveria bassiana (Bals) Vuill. Ind J Exp Biol 32:168-171

Shetty PK, Sabitha M (2009) Economic and ecological externalities of pesticide use in India. In: Peshin R, Dhawan AK (eds) Integrated pest management: innovation-development process. Springer, Netherland. pp 113-129

Shimazu M, Sato H (1996) Media for selective isolation of an entomogenous fungus, Beauveria bassiana (Deuteromycotina: Hyphomycetes). Appl Entomol Zool 31(2):291-298

Strasser H, Vey A, Butt TM (2001) Are there any risks in using entomopathogenic fungi for pest control with particular reference to the bioactive metabolite of Metarhizium, Tolypocladium and Beauveria species. Biocont Sci Technol 10:717-735 Valero-Jimenez CA, Wiegers H, Zwaan BJ, Koenraadt CJ, van Kan JA (2016) Genes involved in virulence of the entomopathogenic fungus Beauveria bassiana. J Invertebr Pathol 133:41-49

Varma A, Tandan BK, Singh K (1988) First record of Beauveria bassiana (Balsamo) Vuillemen, an entomogenous fungus from the sugarcane defoliator Phytoscaphus sp. (Coleoptera: Curculionidae) from India. Curr Sci 57(7):396

Vilgalys R, Hester M (1990) Rapid genetic identification and mapping of enzymatically amplified ribosomal DNA from several Cryptococcus species. J Bacteriol 172:4238-4246

\section{Submit your manuscript to a SpringerOpen ${ }^{\circ}$ journal and benefit from:}

- Convenient online submission

- Rigorous peer review

- Open access: articles freely available online

High visibility within the field

- Retaining the copyright to your article

Submit your next manuscript at $\boldsymbol{\nabla}$ springeropen.com 